\title{
Hybrid Material: Steel And Aluminum, Fiberglass Reinforced
}

\author{
Muhammad Afiq Mohd Shuhaimi ${ }^{1}$,Darulihsan Abdul Hamid ${ }^{1}$ Azman Ismail ${ }^{2}$, Mohd Afendi Rojan ${ }^{3}$, \\ Bakhtiar Ariff Baharudin ${ }^{2}$, Mohd Saidi Mohd Saad ${ }^{2}$, Kamarul Nasser Mokri², Abdul Malik Mohd Ali ${ }^{4}$ \\ ${ }^{1}$ University Kuala Lumpur Institute of Product Design And Manufacturing, Malaysia. \\ ${ }^{2}$ University Kuala Lumpur Malaysian Institute of Marine Engineering Technology, Malaysia. \\ ${ }^{3}$ School of Mechatronic Engineering, Universiti Malaysia Perlis, Malaysia. \\ ${ }^{4}$ Universiti Kuala Lumpur British Malaysian Institute, Malaysia. \\ *Email: fiq_kaydey11@yahoo.com.my
}

\begin{abstract}
The hybrid material is a new invention of the material combination which can be used in the shipbuilding industries. The main purpose of the invention is to have the lightweight structure and anti corrosion with better strength. This material called hybrid because of the combination of the metal and fiberglass, whereby the resin as an adhesive. This hybrid material can be used for new marine construction and naval structure. The new characteristic of this hybrid material is a combination of each advantage of aluminium, steel and fiberglass. This project is very useful for shipbuilding industries in order to produce the lightweight and anti-corrosion hybrid material.
\end{abstract}

Keywords: hybrid material, shipbuilding, lightweight, anti-corrosion, material combination.

\section{Introduction}

Composite sandwich structures were found widespread acceptance in advanced for structural application of aerospace and civil engineering. This sandwich structure has many functions to aerospace but yet major use as the primary load carrying parts. There are not widespread acceptance in other transportation due to has yet to know the ability of the sandwich panels. In ships, composite sandwich structures are used to full extend.

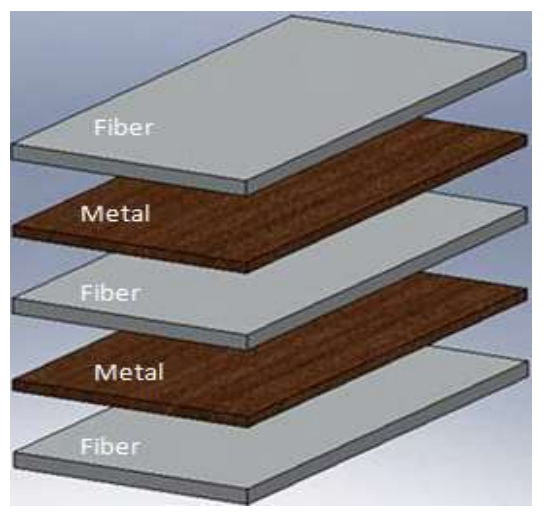

Fig. 1: Sandwich panel

The main factor for using composite sandwich structures in ship hulls is low structural weight [1]. In previous study, CFRP-sandwich version gave about $60 \%$ weight saving compared to the steel version [2]. Other important features are the non-corrosive material that leads much lower maintenance cost in the lifetime of the structure. There are some research done before on developing this specification of material such as using aramid, carbon fiber and etc. for getting more strengthen of material, but is most expensive material [3]. In naval applications; a non-magnetic hull material is very advantageous and sometimes necessary. High operational cost faced by the shipbuilding industry. It does consist of aspect of high density, and a corrosion velocity that 
requires the use of expensive methods for its prevention. Then, the high speed ship is the sensitive to the weight to perform the better fuel consumption [4,5]. These make sense of the national maritime defensive to use composite sandwich structures for their ship as stealth to avoid the mines under the sea. Besides that, hull is low acoustic and thermal signatures and this sandwich panels are inherently blast resistant compared to steel or single skin structures [4].

The manufacturing of this material should be based on their regulation that can be compliant to be applied for. The fabrication of this material for marine application must be obtained the result as discuss before. Based on previous studies, the manufacturing of hybrid material must follow the concept of interlaminar for the better bonding [6]. This interlaminar is such a concept of pyramid which to be applied as a sandwich panel. Besides that, the infusion technique is the best choice of the bonding method for this non- similar material [7].

Ship caters various objectives i.e high speed ferries and naval craft surely the speed and agility are the main priority, low weight becomes the most important design factor. Optimization ways are to minimize the structural weight and go for higher speed.

\section{Experimental setup}

The experiment was run using flow resin method without autoclave compression.

\subsection{Materials and Methods}

Hybrid metal fiberglass reinforced material is a simple project fabricated in order to produce lightweight and anti-corrosion material. This material was developed by using infusion technique. Materials used to produce the hybrid material are CSM 450gsm and perforated aluminum and steel thin sheet with the thickness of $0.9 \mathrm{~mm}$. This material was developed using sandwich concept and applied the flow epoxy resin as their adhesive. The hybrid materials were arranged in multilayer (sandwich) form and then will be bagging together in vacuum mode. After that, the flow of resin was applied into these multilayers of prepared materials. The specimen was then let to harden for 6 hours to cure completely.
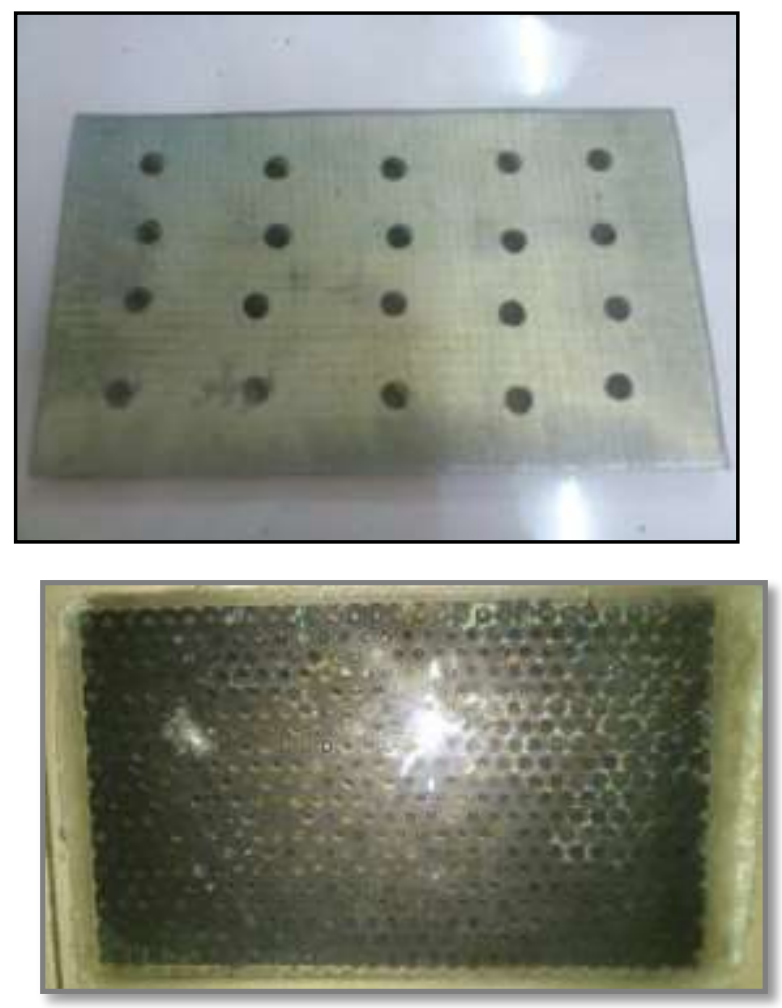

Fig. 2a \& b: Hybrid aluminum (upper) and hybrid steel (below)material. 


\section{Result and Discussion}

The weight of the hybrid material measured and compared with the weight of the monolithic material either aluminum or steel. The comparison weight for hybrid and monolithic aluminum material is done with the same dimension of $240 \times 120 \times 10 \mathrm{~mm}$.

The weight reduction of these materials were obtained and compared to the monolithic metal either aluminum or steel. The data shown in Table 1 below where the hybrid aluminum have the $11 \%$ reduction weight of the monolithic aluminum. The hybrid steel is $40 \%$ reduction compared to steel. The specimen was then sent for tensile test as shown in Figure 3 and Table 2 respectively.

TABLE I:Percentage of weight reduction compare to monolithic material.

\begin{tabular}{|l|l|l|}
\hline Speciment & Weight & Weight Reduction \% \\
\hline hybrid steel & 1972 & \multirow{2}{*}{$40 \%$} \\
steel & 3332 & \\
\cline { 1 - 2 } hybrid aluminum & 1632 & \multirow{2}{*}{$11 \%$} \\
\cline { 1 - 2 } aluminum & 1836 & \\
\hline
\end{tabular}
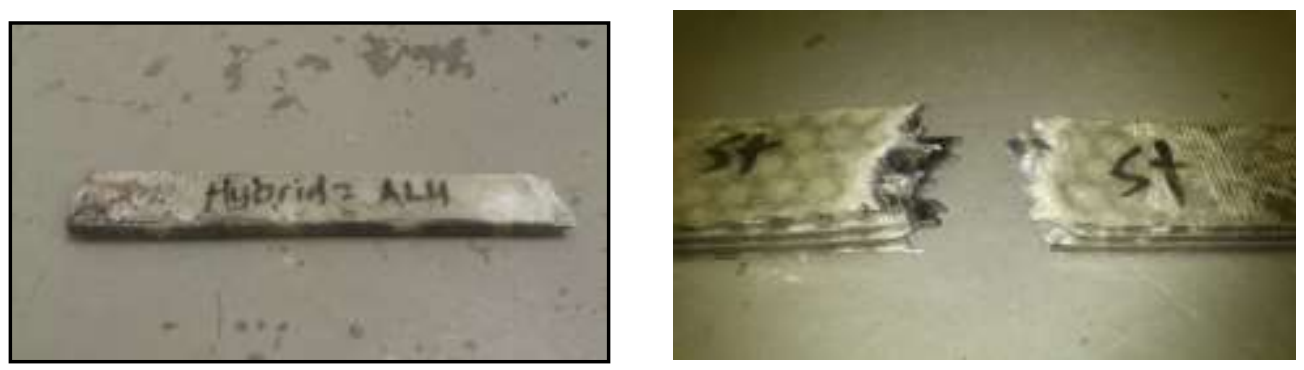

Fig. 3: specimen after tensile test

TABLE II: Result of tensile test

\begin{tabular}{lllll}
\hline No & Material & Load $(\mathbf{k N})$ & Cross Area $(\mathbf{m})$ & $\begin{array}{l}\text { Tensile } \\
\text { strength } \\
\text { (Mpa) }\end{array}$ \\
\cline { 4 - 5 } & & & $20 \mathrm{mmx} 10 \mathrm{~mm}$ & \\
\hline $\mathbf{1}$ & & & \\
$\mathbf{2}$ & Steel & 73 & 0.0002 & 365 \\
$\mathbf{3}$ & Hybrid steel & 81.2 & 0.0002 & 406 \\
$\mathbf{4}$ & Aluminium & 54 & 0.0002 & 270 \\
\hline
\end{tabular}

The result of the tensile strength is tabular. The result obtained could be compared between the steel and hybrid steel, aluminum and hybrid aluminum. The result shown that the hybrid steel of 406MPa was more stronger than monolithic steel of 365MPa. The same condition applies for aluminium specimen in which the hybrid aluminium of $302 \mathrm{MPa}$ was more stronger than monolithic aluminium of 270MPa. In percentage, the strength of the hybrid material will be increased about $10 \%$ than monolithic steel and aluminum hybrid will be increased about $11 \%$ from their monolithic aluminum respectively. 


\section{Conclusion}

These hybrid materials were successfully developed. These materials could be used to produce a lightweight and stronger structure. Based on this study, several conclusions can be made as follows;

a. Hybrid materials produced a weight saving between $11 \%$ and $40 \%$ for steel and aluminium respectively.

b. Hybrid materials increases the strength up to $12 \%$ for both materials.

\section{Acknowledgement}

The author would like to thank the Universiti Kuala Lumpur Malaysian Institute of Marine Engineering Technology (UniKL MIMET), Institute of Product Design and Manufacturing (UniKL IPROM), and Universiti Malaysia Perlis (UniMAP) for providing the proper materials and facilities for this project.

\section{References}

[1] D. Zenkert, Andrey Shipsha, Peter Bull, Brian Hayman. Damage tolerance assessment of composite sandwich panels. (2005). Composites Science and Technology 65 (2005) 2597-2611.

http://dx.doi.org/10.1016/j.compscitech.2005.05.026

[2] Sven-Erik Hellbratt (n.d) Time for light weight composite materials to enter the merchant shipbuilding. Accessed from www.composite-superstructure.com/Time_For.pdf

[3] Ion Dinca, Adriana Stefan, Ana Stan, Aluminium/glass fibre and aluminium/ carbon fibre hybrid laminates, INCAS BULLETIN, Volume 2, Number 2/ 2010, pp. 33-39.

[4] Juan C. Suarez, Miguel A. Herreros (2008). New Fiber-Metal Hybrid Laminated Material. Accessed from http://oa.upm.es/4195/1/INVE_MEM_2008_58980.pdf.

[5] MathivananPeriasamy, Balakrishnan Manickam, Krishnan Hariharasubramanian, Impact Properties of AluminiumGlass Fiber Reinforced Plastics Sandwich Panels, Materials Research. 2012; 15(3): 347-354.

[6] J. Sinke, Manufacturing Principles For Fiber Metal Laminates. Accessed from http://www.iccmcentral.org/Proceedings/ICCM17proceedings/Themes/Materials/FIBRE\%20METAL\%20LAM\%20\&\%20HYB\%20CO MP/D5.1\%20Sinke.pdf

[7] Alfred C. Loos, GokerTuncol, Roberto J. Cano, Brain J. Jensen, Stephen J. Hales, and Joel A. Alexa (2008) Fabrication Of Fiber/Metal Hybrid Composites By The Vartm Process, FPCM-9 (2008), The $9^{\text {th }}$ International Conference on Flow Processes in Composite Materials Montréal (Québec), Canada 8 10 July 2008. 